\title{
Sistem Seleksi Calon Siswa Bidik Misi Menggunakan Metode Simple Additive Weighting
}

\author{
Budi Hartanto'); Bramasto Wiryawan Yudanto ${ }^{2)}$ \\ 1) Program Studi Informatika, STMIK Sinar Nusantara \\ 2)Program Studi D3 Teknologi Informasi, STMIK Sinar Nusantara \\ 1)budihartanto@sinus.ac.id; 2)bramasto@sinus.ac.id
}

\begin{abstract}
Vocational Senior High School of Muhammadiyah 2 Sukoharjo, opens Student Scholarship of Bidik Misi to accept new students in every admission period of academic year. This school has difficulty to decide the candidates of scholarship grantee. In this research, there is solution by creating selection system to select the candidate of scholarship grantee using Simple Additive Weighting method. This research uses parents' income, family living cost, students' grades, and students' achievement. This research also uses a Usecase Diagram to design the system. To test the system, this research uses Blackbox testing method. There are 25 valid questions in research result so that this application is suitable to select the new students. Based in its result, additive simple weighting method can be used as a method to support decision, especially in the selection of scholarship grantee candidates.
\end{abstract}

Keywords: Simple Additive Weighting, Decision Support System, New student selection.

\section{PENDAHULUAN}

Penentuan calon siswa baru dengan jalur bidik misi merupakan suatu hal yang sangat penting bagi pihak sekolah. Proses seleksi atau penentuan calon siswa tersebut sangat menentukan hasil yang akan diperoleh. SMK Muhmmadiyah 2 Sukoharjo dalam melakukan seleksi terhadap calon siswa baru menggunakan jalur bidik misi mempunyai kendala dalam hal proses seleksi, secara lebih spesifik kendala yang dialami yaitu perhitungan poin bagi seluruh pendaftar program bidik misi. Perhitungan poin yang diinginkan oleh pihak sekolah tidak hanya berdasarkan nilai, akan tetapi terdapat beberapa kriteria dalam proses seleksi tersebut.

Dalam ilmu pengetahuan terdapat suatu metode yang dapat digunakan untuk menentukan pilihan dari beberapa pilihan, metode Simple Additive Weighting merupakan satu metode yang berdasarkan pada rata-rata pembobotan [3]. Metode Simple Additive Weighting dapat membantu sekolah dalam menentukan calon siswa baru yang berkualitas sesuai dengan kriteria-kriteria yang telah ditentukan [1]

Berdasarkan uraian yang telah disampaikan diatas, maka dalam hal ini peneliti yang juga sebagai pengembang system membuatkan suatu perancangan system aplikasi untuk dapat melakukan seleksi terhadapa siswa baru di SMK Muhammadiyah 2 Sukoharjo dengan menggunakan metode pendukung keputusan yaitu menggunakan Simple Additive Weigthing.

\section{TINJAUAN PUSTAKA}

\subsection{Sistem Pendukung Keputusan}

Sistem Pendukung Keputusan atau dalam Bahasa inggris Decision Suport System merupakan suatu system yang dirancang untuk mendukung seluruh tahapan dalam pengambilan keputusan mulai dari identifikasi masalah, pemilihan data yang terkait dengan kasus, menentukan pendekatan sampai dengan melakukan evaluasi terhadap hasil pengambilan keputusan [1].

\subsection{Simple Additve Weighting (SAW)}

Metode pendukung keputusan yaitu Simple Additive Weigthing merupakan suatu metode dengan konsep penjumlahan terbobot mencari cara mencari rating atau nilai poin dari seluruh alternatif pada semua atribut atau kriteria [4]. Metode ini juga membutuhkan proses normalisasi matriks kesuatu skala yang dapat dibandingkan dalam rating alternative yang ada [2]. Langkah -langkah dalam melakukan proses Simple Additive Weighting yaitu [5].

1) Menentukan kriteria yang akan dijadikan sebagai parameter dalam proses penentuan

2) Menentukan rating kecocokan pada setiap alternatif disemua kriteria

3) Membuat matriks normalisasi berdasarkan persamaan pada setiap atribut. 
4) Melakukan Pembobotan Preferensi

5) Hasil proses perangkingan yang merupakan hasil rekomendasi dari metode SAW tersebut.

Untuk lebih jelasnya berikut rumusan untuk mencari nilai rating kinerja ternormalisasi.

$r i j=\left[\frac{X i j}{\operatorname{Max} X i j}\right]$

Keterangan :

$r_{i j} \quad=$ Nilai rating kinerja ternormalisasi

$X_{i j}=$ Nilai atribut yang dimiliki alternatif

Kriteria:

$\operatorname{Max} X_{i j}=$ Nilai terbesar dari setiap kriteria

Min $X_{i j}=$ Nilai terkecil dari setiap kriteria

Dari rumusan diatas $r_{i j}$ merupakan suatu rating ternormalisasi dari setiap atribut, dimana untuk menentukan prefensi untuk setiap alternatif adalah sebagai berikut.

$V_{i=} \sum_{j=1}^{n} w_{j} \quad r_{i j}$

Keterangan:

$\mathrm{V}_{\mathrm{i}}=$ Ranking untuk setiap alternative

$\mathbf{w}_{\mathrm{j}}=$ Nilai bobot dari setiap kriteria

$r_{i j}=$ Nilai rating kinerja ternormalisasi

\section{METODE PENELITIAN}

\subsection{Pengumpulan Data}

Dalam tahapan ini peneliti melakukan pengumpulan data yang terkait dengan kebutuhan dari sistem pendukung keputusan tersebut. Data yang dikumpulkan yaitu data calon siswa yang meliputi data nama pendaftar.Data kriteria yang digunakan sebagai seleksi siswa yaitu data penghasilan orang tua, jumlah tanggungan orang tua, nilai rata-rata ijazah, dan data penghargaan yang pernah diperoleh.

\subsection{Analisa Sistem}

Pada tahapan ini Peneliti melakukan analisa terhadap kelemahan dan kebutuhan sistem pendukung keputusan tersebut. Langkah ini meliputi menentukan bobot kriteria sampai dengan menghitung rumusan dengan metode Simple Additive Weighting.

\subsection{Perancangan Sistem}

Peneliti dalam tahapan ini melakukan perancangan sistem dengan menggunakan
Use Case dan Class Diagram langkah ini digunakan agar mudah dalam proses pengembangan sistem pendukung keputusan tersebut.

\subsection{Implementasi}

Tahapan implementasi merupakan tahapan yang melakukan proses pembuatan sistem aplikasi, langkah yang dilakukan yaitu mengetikan kode program dan melakukan pemasangan aplikasi pada sisi server tersebut.

\subsection{Pengujian}

Dalam tahapan pengujian sistem langkah yang dilakukan yaitu meguji kineja dari berbagai fitur dari aplikasi menggunakan metode Blackbox testing.

\section{HASIL DAN PEMBAHASAN}

\subsection{Analisa Menggunakan SAW}

A. Menentukan Data Alternatif

Data alternatif merupakan suatu data yang didapatkan dari hasil proses pendataan terhadap pendaftar calon siswa baru pada jalur bidik misi, berikut data alternatif.

Tabel 1. Data Alternatif

\begin{tabular}{|l|l|}
\hline No & \multicolumn{1}{|c|}{ Alternatif (r) } \\
\hline R1 & Ade Imsa Oktaviani \\
\hline R2 & Afifah Arum Fatimah \\
\hline R3 & Alifah Andita Siwi \\
\hline R4 & Ana Dwi Safitri \\
\hline R5 & Anisa Septiani \\
\hline R6 & Aprilia Ramadani \\
\hline R7 & Awalinda Ramanda Hari \\
\hline R8 & Aziz Pratama \\
\hline R9 & Dika Ayu Setiyaningsih \\
\hline R10 & Dwi Utami \\
\hline R11 & Fitri Suci Romadhani \\
\hline R12 & Galuh Cahyaning Tias \\
\hline R13 & Icha Larassati Priyana \\
\hline R14 & Ika Nadia Elfandari \\
\hline
\end{tabular}

B. Menentukan Data Kriteria / Atribut Kriterai dalam melakukan seleksi terhadap calon siswa baru di SMK Muhammadiyah 2 Sukoharjo adalah sebagai berikut.

1) Penghasilan Orangtua
a. <1Juta
$: 40$ 

b. 1Juta s/d 2juta
c. 2Juta s/d 3 Juta
$: 20$
d. >3 Juta
$: 10$

2) Jumlah Tanggungan Anak
a. $5: 35$
b. $4: 25$
c. $3: 20$
d. $2: 15$
e. $1: 5$

3) Rata-rata nilai ljazah
a. $<70$
$: 20$
b. $70 \mathrm{~s} / \mathrm{d} 80$
$: 30$
c. $>80$
$: 50$

4) Penghargaan
a. Tidak Ada : 5
b. Kabupaten :15
c. Provinsi :20
d. Nasional :25
e. Internasional : 35

C. Memasukkan Nilai Atribut Alternatif

Setiap alternatif mempunyai atribut yang bernilai setelah dilakukan diskritisasi sesuai dengan poin pada setiap sub kriteria maka didapatkan hasil sebagai berikut.

Tabel 2. Data Nilai Alternatif Setiap Atribut

\begin{tabular}{|c|c|c|c|c|c|}
\hline No & Nama Pendaftar & j1 & $\mathrm{j} 2$ & $\mathrm{j} 3$ & $\mathrm{j} 4$ \\
\hline 1 & $\begin{array}{l}\text { Ade Imsa } \\
\text { Oktaviani }\end{array}$ & 30 & 25 & 20 & 5 \\
\hline 2 & $\begin{array}{l}\text { Afifah Arum } \\
\text { Fatimah }\end{array}$ & 40 & 35 & 50 & 5 \\
\hline 3 & Alifah Andita Siwi & 20 & 25 & 30 & 5 \\
\hline 4 & Ana Dwi Safitri & 20 & 35 & 30 & 5 \\
\hline 5 & Anisa Septiani & 30 & 20 & 30 & 15 \\
\hline 6 & Aprilia Ramadani & 40 & 15 & 30 & 15 \\
\hline 7 & $\begin{array}{l}\text { Awalinda } \\
\text { Ramanda }\end{array}$ & 30 & 10 & 50 & 5 \\
\hline 8 & Aziz Pratama & 30 & 15 & 30 & 5 \\
\hline 9 & Dika Ayu S & 40 & 20 & 50 & 20 \\
\hline 10 & Dwi Utami & 10 & 15 & 30 & 5 \\
\hline 11 & $\begin{array}{l}\text { Fitri Suci } \\
\text { Romadhani }\end{array}$ & 40 & 15 & 30 & 5 \\
\hline 12 & $\begin{array}{l}\text { Galuh Cahyaning } \\
\text { Tias }\end{array}$ & 30 & 25 & 20 & 15 \\
\hline 13 & $\begin{array}{l}\text { Icha Larassati } \\
\text { Priyana }\end{array}$ & 20 & 15 & 50 & 5 \\
\hline 14 & $\begin{array}{l}\text { Ika Nadia } \\
\text { Elfandari }\end{array}$ & 10 & 35 & 20 & 5 \\
\hline
\end{tabular}

D. Menentukan Rating Ternormalisasi
Pada kasus ini peneliti memberikan contoh perhitungan penentan rating ternormalisasi pada alternatif $\mathrm{A} 1$ (Penghasilan Orangtua).

$r_{i j}=\left\{\frac{X_{i j}}{\operatorname{Max} X_{i j}}\right\}$

$r 1=\frac{30}{40}$

$r 1=0,750$

$r 2=\frac{40}{40}$

$r 2=1,000$

Dengan menggunakan langkah yang sama sesuai dengan kaidah perhitungan rumus rating ternormalisasi maka didapatkan hasil sebagai berikut.

Tabel 3. Rating Ternormalisasi

\begin{tabular}{|c|c|c|c|c|c|}
\hline No & Alternatif & J1 & J2 & J3 & J4 \\
\hline 1 & Ade Imsa O & 0,750 & 0,714 & 0,400 & 0,250 \\
\hline 2 & $\begin{array}{l}\text { Afifah Arum } \\
\text { F }\end{array}$ & 1,000 & 1,000 & 1,000 & 0,250 \\
\hline 3 & $\begin{array}{l}\text { Alifah Andita } \\
\text { S }\end{array}$ & 0,500 & 0,714 & 0,600 & 0,250 \\
\hline 4 & $\begin{array}{l}\text { Ana Dwi } \\
\text { Safitri }\end{array}$ & 0,500 & 1,000 & 0,600 & 0,250 \\
\hline 5 & $\begin{array}{l}\text { Anisa } \\
\text { Septiani }\end{array}$ & 0,750 & 0,571 & 0,600 & 0,750 \\
\hline 6 & Aprilia R & 1,000 & 0,429 & 0,600 & 0,750 \\
\hline 7 & $\begin{array}{l}\text { Awalinda R } \\
\mathrm{H}\end{array}$ & 0,750 & 0,286 & 1,000 & 0,250 \\
\hline 8 & $\begin{array}{l}\text { Aziz } \\
\text { Pratama }\end{array}$ & 0,750 & 0,429 & 0,600 & 0,250 \\
\hline 9 & Dika Ayu S & 1,000 & 0,571 & 1,000 & 1,000 \\
\hline 10 & Dwi Utami & 0,250 & 0,429 & 0,600 & 0,250 \\
\hline 11 & Fitri Suci R & 1,000 & 0,429 & 0,600 & 0,250 \\
\hline 12 & Galuh C T & 0,750 & 0,714 & 0,400 & 0,750 \\
\hline 13 & $\begin{array}{l}\text { Icha } \\
\text { Larassati P }\end{array}$ & 0,500 & 0,429 & 1,000 & 0,250 \\
\hline 14 & Ika Nadia E & 0,250 & 1,000 & 0,400 & 0,250 \\
\hline
\end{tabular}

E. Menentukan Pembobotan Preferensi

Pada tahapan ini dalam menentukan preferensi pembobotan, maka langkah yang pertama menentukan bobot dari masing masing atribut atau kriteria dimana bobot dari masing-masing kriteria tersebut adalah sebagai berikut.

a. Penghasilan Orangtua $(0,4)$

b. Jumlah Tanggungan Anak $(0,3)$ 
c. Nilai ljazah $(0,2)$

d. Penghargaan $(0,1)$

Pada kasus ini penulis memberikan satu contoh perhitungan dalam menentukan $V_{i}$. Berikut perhitungan untuk mencari nilai preferensi.

$$
\begin{aligned}
v 1 & =w j 1 \times r 1 \\
& =0,4 \times 0,750 \\
& =0,300 \\
v 1 & =w j 2 \times r 2 \\
& =0,3 \times 0,714 \\
& =0,214
\end{aligned}
$$

\begin{tabular}{|c|c|c|c|c|c|}
\hline No & Alternatif & J1 & J2 & J3 & J4 \\
\hline 1 & Ade Imsa O & 0,300 & 0,214 & 0,080 & 0,025 \\
\hline 2 & Afifah Arum F & 0,400 & 0,300 & 0,200 & 0,025 \\
\hline 3 & $\begin{array}{l}\text { Alifah Andita } \\
\text { S }\end{array}$ & 0,200 & 0,214 & 0,120 & 0,025 \\
\hline 4 & $\begin{array}{l}\text { Ana Dwi } \\
\text { Safitri }\end{array}$ & 0,200 & 0,300 & 0,120 & 0,025 \\
\hline 5 & Anisa Septiani & 0,300 & 0,171 & 0,120 & 0,075 \\
\hline 6 & Aprilia R & 0,400 & 0,129 & 0,120 & 0,075 \\
\hline 7 & Awalinda $\mathrm{R} \mathrm{H}$ & 0,300 & 0,086 & 0,200 & 0,025 \\
\hline 8 & Aziz Pratama & 0,300 & 0,129 & 0,120 & 0,025 \\
\hline 9 & Dika Ayu S & 0,400 & 0,171 & 0,200 & 0,100 \\
\hline 10 & Dwi Utami & 0,100 & 0,129 & 0,120 & 0,025 \\
\hline 11 & Fitri Suci R & 0,400 & 0,129 & 0,120 & 0,025 \\
\hline 12 & Galuh C T & 0,300 & 0,214 & 0,080 & 0,075 \\
\hline 13 & $\begin{array}{l}\text { Icha Larassati } \\
\mathrm{P}\end{array}$ & 0,200 & 0,129 & 0,200 & 0,025 \\
\hline 14 & Ika Nadia E & 0,100 & 0,300 & 0,080 & 0,025 \\
\hline
\end{tabular}

Dengan menggunakan langkah yang sama untuk mencari nilai preferensi maka didapatkan hasil sebagai berikut.

Tabel 4. Nilai Preferensi

\section{F. Melihat Hasil Alternatif}

Untuk menentukan hasil seleksi maka pada tahapan ini yaitu menjumlahkan nilai preferensi pada setiap atribut yang ada pada setiap alternatif. Maka didapatkan hasil sebagai berikut.

Tabel 5 Hasil Alternatif

\begin{tabular}{|l|l|l|}
\hline No & Alternatif & $\mathbf{V}_{\mathbf{i}}$ \\
\hline 1 & Afifah Arum $\mathrm{F}$ & 0,925 \\
\hline 2 & Dika Ayu S & 0,871 \\
\hline 3 & Aprilia R & 0,724 \\
\hline 4 & Fitri Suci R & 0,674 \\
\hline
\end{tabular}

\begin{tabular}{|l|l|l|}
\hline No & Alternatif & $\mathbf{V}_{\mathbf{i}}$ \\
\hline 5 & Galuh C T & 0,669 \\
\hline 6 & Anisa Septiani & 0,666 \\
\hline 7 & Ana Dwi Safitri & 0,645 \\
\hline 8 & Ade Imsa O & 0,619 \\
\hline 9 & Awalinda R H & 0,611 \\
\hline 10 & Aziz Pratama & 0,574 \\
\hline 11 & Alifah Andita S & 0,559 \\
\hline 12 & Icha Larassati P & 0,554 \\
\hline 13 & Ika Nadia E & 0,505 \\
\hline 14 & Dwi Utami & 0,374 \\
\hline
\end{tabular}

SMK Muhammadiyah 2 Sukoharjo dalam melakukan seleksi terhadap calon siswa baru menggunakan jalur bidik misi, membuka kuota 5 calon siswa baru. Berdasarkan hasil tersebut maka siswa yang diterima adalah 5 calon siswa dengan peringkat 5 besar.

\subsection{Perancangan Sistem}

1. Use Case Diagram

Sistem aplikasi yang dibuat menggunakan konsep multi user atau banyak pengguna. Pengguna yang dapat melakukan akses terhadap aplikasi ini diantaranya panitia, ketua dan juga pendaftar. Masing-masing pengguna mempunyai haka tau level yang berbeda-beda sesuai dengan fitur yang tersedia. Panitia bertugas memasukan data dan melakukan analisa data. Pengguna dengan ketua bertugas melakukan konfirmasi terhadap hasil alternatif yang ada. Pengguna dengan pendaftar dapat melihat hasil alternatif atau hasil seleksi tersbut. Untuk melihat alur dari sistem yang digunakan dalam melakukan seleksi terhadap siswa baru, maka dapat dilihat dari desain perancangan sistem berikut.

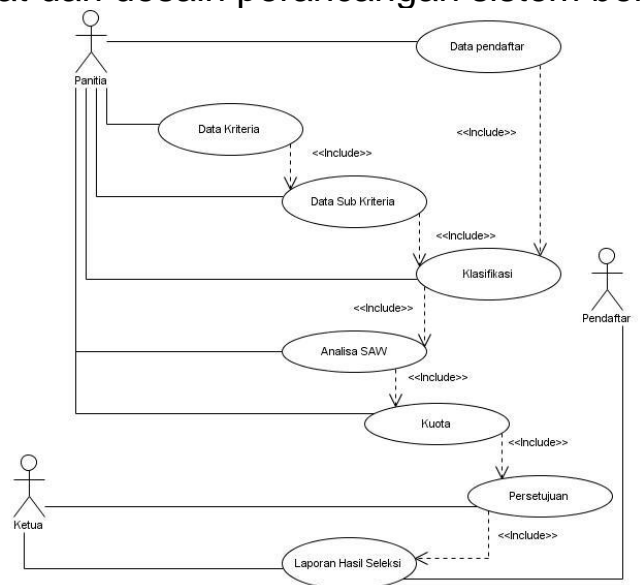

Gambar 1. Use Case Diagram

Pada Use Case Diagram tersebut terdapat 
3 aktor yang menggunakan aplikasi pendukung keputusan. Panitia dapat melakukan akses pada data kriteria, data sub kriteria, data klasifikasi dan proses analisa. Adapun aktor dengan level ketua melakukan persetujuan dan melihat hasil. Aktor dengan level pendaaftar dapat melihat hasil seleksi.

\subsection{Implementasi Sistem}

Form analisa merupakan suatu form yang digunakan untuk melakukan pembobotan yang nantinya akan dimasukan ke dalam rumusan perhitungan metode Simple Additive Weighting.
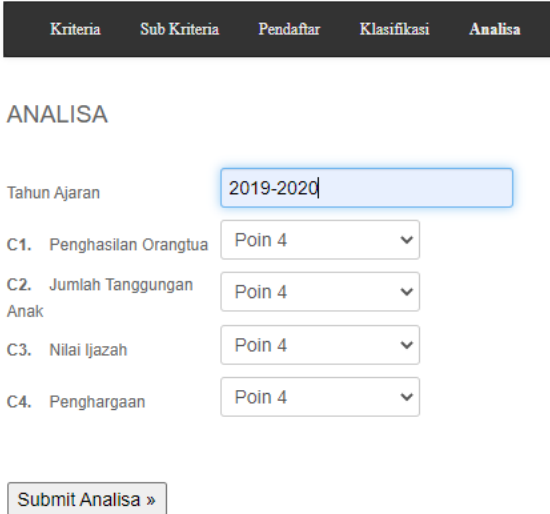

\section{Gambar 2. Form Analisa}

Hasil alternatif merupakan sebuah rekomendasi dari sistem yang telah dibuat. Berikut hasil sistem aplikasi yang menggunakan metode Simple Additive Weighting.

\begin{tabular}{|lll|}
\hline Nama Pendaftar & Nilai & Status \\
\hline Afifah Arum F & 0,925 & DITERIMA \\
\hline Dika Ayu S & 0,871428571 & DITERIMA \\
\hline Aprilia R & 0,723571429 & DITERIMA \\
\hline Fitri Suci R & 0,673571429 & DITERIMA \\
\hline Galuh C T & 0,669285714 & DITERIMA \\
\hline Anisa Septiani & 0,666428571 & DITERIMA \\
\hline Ana Dwi Safitri & 0,645 & DITERIMA \\
\hline Ade Imsa O & 0,619285714 & TIDAK DITERIMA \\
\hline Awvalinda R H & 0,610714286 & TIDAK DITERIMA \\
\hline Aziz Pratama & 0,573571429 & TIDAK DITERIMA \\
\hline Alifah Andita S & 0,559285714 & TIDAK DITERIMA \\
\hline Icha Larassati P & 0,553571429 & TIDAK DITERIMA \\
\hline Ika Nadia E & 0,505 & TIDAK DITERIMA \\
\hline Dwi Utami & 0,373571429 & TIDAK DITERIMA \\
\hline
\end{tabular}

\section{Gambar 3. Hasil Alternatif Sistem}

\subsection{Pengujian}

Untuk memastikan bahwa fungsi dari fiturfitur aplikasi ini dapat bekerja sesuai dengan konsep yang telah dirancang, maka dilakukan pengujian kelayakan sistem menggunakan metode blackbox testing.
Tabel 6 Kelas Uji

\begin{tabular}{|c|l|}
\hline Kelas Uji & \multicolumn{1}{|c|}{ Butir Uji } \\
\hline \multirow{2}{*}{ Fitur Login } & Verifikasi Login \\
\cline { 2 - 2 } & Validasi Login \\
\hline \multirow{4}{*}{ Fitur Input } & Manajemen Kriteria \\
\cline { 2 - 2 } & Manajemen Sub Kriteria \\
\cline { 2 - 2 } & Manajemen Alternatif \\
\hline \multirow{4}{*}{ Fitur Proses } & Klasifikasi \\
\cline { 2 - 2 } & Analisa \\
\cline { 2 - 2 } & Kuota \\
\hline Fitur Output & Hasil Seleksi \\
\hline
\end{tabular}

Dari tabel uji yang tersebut telah dilakukan pengujian terhadap butir uji pada setiap fitur tersebut. Berdasarkan hasil pengujian tersebut, seluruh butir uji dinyatakan valid atau sesuai dengan fungsi-fungsi yang telah direncanakan.

\section{PENUTUP}

Berdasarkan uraian dari bab sebelumnya dapat disimpulkan bahwa:

1. Sistem Pendukung Keputusan dalam melakukan proses seleksi terhadap calon siswa baru jalur bidik misi di SMK Muhammadiyah 2 Sukoharjo yang dibuat oleh penulis sudah sesuai dengan proses analisa dengan metode Simple Additive Weighting. Hal tersebut dibuktikan dengan hasil proses perhitungan pembobotan sampai dengan memperoleh nilai pada setiap alternatif. dimana hasil sistem sama dengan proses analisa perhitungan secara manual.

2. Pada proses pengujian Sistem aplikasi pendukung keputusan yang telah dibuat oleh Penulis, dengan menggunakan jumlah skenario pengujian sebanyak 25, hasil nilai valid sebanyak 25 . Maka system dapat dinyatakan layak untuk digunakan sesuai dengan konsep pendukung keputusan.

\section{DAFTAR PUSTAKA}

[1] Anita Dewi S, Muhammad M, and Sri Hartati, 2017. "Sistem Pendukung Keputusan Perankingan Calon Siswa Baru Jalur Undangan Menggunakan Simple Additive Weighting (Studi Kasus : Smk Bumi Nusantara Wonosobo)," Seminar Nasional Teknologi Informasi dan Multimedia 2017. STMIK AMIKOM Yogyakarta, 4-7 Februari 2017 ISSN: 2302-3805. 
[2] Hanifa, Muhamad Muslihudin, Sri Hartati. 2016. Sistem Pendukung Keputusan Menentukan Besar Gaji Untuk Guru Honorer Di Kabupaten Pesawaran Menggunakan Metode Fuzzy SAW.Jurnal Teknologi, Vol. 09 No.01 Juni 2016, hal. 83-88. IST Akprind. Yogyakarta.

[3] Lena Magdalena, Abdul Rachman. 2017. Aplikasi Pendaftaran Siswa Baru Dengan Sistem Seleksi Menggunakan Metode Simple Additive Weighting (SAW) Pada Smk Miftahul Huda Ciwaringin. JURNAL DIGIT, Vol. 7 No.1 Mei 2017, pp. 38 49 ISSN: 2088-589.

[4] Muhamad Muslihudin \& A. Wulan Arumita. (2016). Pembuatan Model Penilaian Proses Belajar Mengajar Perguruan Tinggi Menggunakan Fuzzy Simple Additive Weighting (SAW) (Studi: STMIK Pringsewu)

[5] Wulandari, Ahmad Mustofa, Ponidi, Muhamad Muslihudin, Firza Adi Firdiansah. (2016). Decision Support System Pemetaan Lahan Pertanian Yang Berkualitas Untuk Meningkatkan Hasil Produksi Padi Menggunakan Metode Simple Additive Weighting (SAW). SEMNASTEKNOMEDIA. AMIKOM Yogyakarta 